\title{
Discursos docentes sobre a "aceitação" da inclusão de pessoas trans na escola
}

\author{
Gisele Martins Ferreira* \\ Meiri Aparecida Gurgel de Campos Miranda**
}

\section{Resumo}

As pessoas trans estão expostas a diversas vulnerabilidades na sociedade. Este artigo objetiva conhecer as dificuldades de "aceitação" das pessoas trans na comunidade escolar da rede estadual da região do ABC Paulista, com base nos discursos docentes e da gestão. Para tanto, foram realizadas entrevistas com quatro professores e três membros da equipe de gestão escolar, em uma escola que recebeu alunos trans. Os dados foram submetidos à análise de discurso. Os principais entraves para a inclusão de pessoas trans estão relacionados à genitalização de relações sociais por parte dos docentes e à falta de apoio familiar. $\mathrm{O}$ acolhimento é facilitado a partir da ação de uma equipe gestora engajada com a questão.

Palavras-chave: Trans, gênero, escola pública

\section{Teacher's speeches about the "acceptance" of in- cluding trans people in school}

\section{Abstract}

Trans people are exposed to various vulnerabilities in society. This article aims to understand the difficulties of "acceptance" of trans people in the school community, based on the teaching and discourses. For this, interviews were conducted with four teachers and three school managers, in a public school of the ABC Paulista that received trans students. The data were submitted to Discourse Analysis. The main obstacles to the inclusion of trans people are related to the genitalization of social relations

\footnotetext{
* Mestra em Ensino e História das Ciências e da Matemática - Universidade Federal do ABC. gisele.scavasini@ufabc.edu.br

** Professora Associada do Centro de Ciências Naturais e Humanas - Universidade Federal do ABC, São Paulo, Brasil. meiri.miranda@ufabc.edu.br
} 
by teachers and the lack of family support. The reception is facilitated by the action of a management team engaged.

Keywords: trans, gender, public school

\section{Discursos de docente sobre la "aceptación" de la inclusión de personas trans en la escuela}

\section{Resumen}

Las personas trans están expuestas a diversas vulnerabilidades en la sociedad. Este artículo tiene como objetivo comprender las dificultades de "aceptación" de las personas trans en la comunidad escolar, a partir de los discursos de los docentes y equipo gerencial. Para ello, hase hecho entrevistas con cuatro maestros y tres personas del equipo gerencial, en una escuela pública estatal de la región ABC Paulista, que recibió estudiantes trans. Los datos se sometieron a Análisis del Discurso. Los principales obstáculos para la inclusión de las personas trans están relacionados con la genitalización de las relaciones sociales por parte de los docentes y la falta de apoyo familiar. La recepción se ve facilitada por la acción de un equipo de gestión comprometido con el tema.

Palabras clave: Trans, género, escuela pública.

\section{Introdução}

"Você docente, aceita essa pessoa trans como sua aluna?" Certamente a pergunta é descabida. Entretanto, muito se fala na "aceitação" da pessoa trans no ambiente escolar, como se fosse facultativo dar espaço para ela dentro da escola. Esta compreensão pode ter relação com a falaciosa ideia de que as identidades sexuais são dadas e naturais, e que pessoas que não correspondem ao esperado socialmente fizeram uma opção por transgredir a regra ao invés de "ser o que naturalmente é". Essas pessoas em "condições sócio-políticas de transgressão de expectativas de gênero" (MARANHÃO FILHO, 2015, p. 49), isso é, pessoas que se identificam como travestis, transexuais, transgêneros, mulheres trans e homens trans, serão chamadas neste artigo de pessoas trans.

Tem-se uma construção social de que os corpos são divididos binariamente em dois tipos: o primeiro sendo pênis-homem-masculino e o segundo (e certamente menos importante, nessa perspectiva) 
vagina-mulher-feminino (BENTO, 2008). Tal concepção está baseada "na ordem binária do gênero, compõe o dispositivo discursivo do chamado 'determinismo biológico"' (BENTO, 2017, p. 238). Expressar-se fora do que é estereotipado para o sexo de nascimento torna o indivíduo sujeito à necessidade de aceitação, visto que o torna alvo de violências por ser considerado excêntrico demais para ser tolerado, mesmo que não seja essa a sua busca (LOURO, 2004).

Contudo, os padrões de comportamento de cada gênero, tidos como "inevitáveis e 'naturais', têm sido frequentemente forjados nesse complexo processo de definição e autodefinição, tornando a moderna sexualidade central para o modo como o poder atua na sociedade moderna" (WEEKS, 2000, p. 29). A pessoa que se identifica fora dos padrões hegemônicos tem a identidade sexual rotulada como manifestação holística de si, uma vez que não são tidas como "naturais" (NAVARRO-SWAIN, 2000). Desconsideram-se outras tantas facetas que como seres humanos têm, como: gênero, orientação sexual, cor/raça, idade, origem geográfica, deficiências, etc. (JESUS, 2014).

No interior da escola, as pessoas trans são frequentemente discriminadas e expostas à violência e assédio por parte de colegas de classe. Essa violência muitas vezes recebe o aval de professores e outros funcionários, sendo legitimada por "brincadeiras" desrespeitosas realizadas por esses profissionais, quando o discente trans deseja realizar uma denúncia contra colegas abusadores. À pessoa trans resta somente a própria agressividade como proteção (PERES, 2009).

Emerge aí uma estigmatização do "anormal", que é avaliado como inferior ao que é considerado "normal". Neste sentido, a hierarquia de Gayle Rubin esclarece que o "anormal” é o que tem a expressão da sexualidade para além do que a autora denomina de "a Linha" (RUBIN, 2003, p. 26) do que é considerado sexo bom no seu tempo e cultura, vivendo-a dentro da área mais controversa ou do sexo mau. Nesta hierarquia, considera-se sexo "bom" as pessoas heterossexuais, casadas e monogâmicas; a área mais controversa seriam os heterossexuais não casados, masturbadores, homossexuais com relacionamento estável e pessoas promíscuas (independente da orientação sexual); e o sexo "mau" composto por transexuais, 
fetichistas, pessoas que se relacionam entre gerações diferentes e profissionais do sexo (RUBIN, 2003). Dentro desta hierarquia, a pessoa trans se encontra entre as castas mais sujeitas a não "aceitação" social.

Ainda que seja evidente o ganho de visibilidade e representatividade de pessoas de sexualidade não hegemônica na atualidade, estas permanecem abjetas e marcadas. "Processos de estigmatização são aqueles em que as pessoas, ao romperem com os modelos previamente dados pela normatização, ficam marcadas negativamente, depreciadas a ponto de serem desprovidas de direitos a ter direitos [...]" (PERES, 2009, p. 237).

A Declaração Universal de Direitos Humanos (1948), já em seu primeiro artigo, determina que:

Todo ser humano tem capacidade para gozar os direitos e as liberdades estabelecidos nesta Declaração, sem distinção de qualquer espécie, seja de raça, cor, sexo, idioma, religião, opinião política ou de outra natureza, origem nacional ou social, riqueza, nascimento, ou qualquer outra condição (p. 5).

O documento determina que absolutamente nenhuma distinção poderia retirar das pessoas os direitos expostos doravante, contudo ao listar certas distinções também silencia diversas possibilidades de humanidades que existem como sujeitos de direitos. As identidades humanas não citadas são jogadas no inumano, mantidas à margem do direito de ter direitos.

A fim de retomar o direito de ter direitos às pessoas de sexualidade não hegemônica, os Princípios de Yogyakarta (2007) vêm trazer de forma manifesta, através de um vocabulário explícito, que os direitos humanos garantidos desde 1948, com a Declaração Universal de Direitos Humanos, também se aplicam aos sujeitos com diferentes expressões da sexualidade não ligadas ao sexo biológico e reprodutivo. Assim, situações de violência e discriminação relacionadas à sexualidade teriam sido sanadas no documento.

Um marco para o direito de autoidentificação de pessoas trans no Brasil ocorreu em 2018, com a publicação do provimento 
n. ${ }^{\circ} 73$ de 28 de junho de 2018, que “dispõe sobre a alteração de prenome e gênero nos documentos referentes ao Registro Civil de Pessoas Naturais" (STF, 2018, n.p). O documento possibilita o requerimento de alteração de prenome e de gênero sem a necessidade de laudo médico/psicológico de incongruência de gênero.

Conquanto haja documentos oficiais que garantem direitos, incluindo o direito à educação, metade das pessoas trans evade da escola em algum momento da vida (CANTELLI; NOGUEIRA, 2019). As autoras citam como causas para essa interrupção: transfobia, depressão, problemas financeiros, trabalho, exclusão familiar, problema de saúde, desinteresse, fobia social, agressão física, assédio moral, mudança geográfica, abuso sexual e racismo.

Pensando nas vulnerabilidades das pessoas trans, nosso objetivo neste artigo é olhar para o interior da escola para conhecer as dificuldades de "aceitação" das pessoas trans na comunidade escolar, com base nos discursos docentes e da gestão.

Autoras e autores, muitas vezes, se utilizam de caracteres especiais ou letras tidas como neutras, como @, E e X, a fim de construir um texto de gênero neutro. Buscando trazer um texto de maior inteligibilidade, tanto para leitores já versados nas linguagens utilizadas dentro da área de sexualidade quanto para outros públicos, utilizaremos a norma padrão da Língua Portuguesa. Tal estrutura facilita o entendimento para pessoas que não são falantes nativos de Português ou que utilizam softwares de leitura, e ainda para o público que inicia seu estudo sobre as questões da sexualidade.

\section{Metodologia}

O presente artigo deriva da dissertação de mestrado da primeira autora, intitulada “Trans entre nós: Análise da inclusão de pessoas trans na comunidade escolar". A pesquisa foi realizada com docentes voluntários que atuam como professores e equipe gestora em uma escola estadual de Ensino Fundamental Anos Finais (EF), Ensino Médio (EM) e Educação de Jovens e Adultos (EJA), da região do grande $\mathrm{ABC}$, Estado de São Paulo, que recebeu pessoas trans em sua comunidade nos últimos anos. Para este artigo, foram selecionadas as falas referentes a "aceitação" de discentes trans. A 
escolha dos sujeitos de pesquisa foi intencional, tendo como requisito ter vivenciado, seja como docente ou como gestor, a passagem dessas pessoas trans pela escola. Foram entrevistados quatro professores, a diretora, o vice-diretor e a professora coordenadora pedagógica (Quadro 1).

Quadro 1. Caracterização, quanto à formação acadêmica e atuação no ano de 2018, do grupo de docentes e equipe gestora que participou da pesquisa. Os nomes apresentados são fictícios para garantir o anonimato dos voluntários

\begin{tabular}{|c|c|c|c|}
\hline Pseudônimo & Formação acadêmica & Atuação & $\begin{array}{l}\text { Séries em que } \\
\text { atuou }\end{array}$ \\
\hline Carlos & $\begin{array}{l}\text { Licenciatura em Estudos Sociais, } \\
\text { História, Geografia e Pedagogia } \\
\text { Pós-graduação em Meio Ambiente }\end{array}$ & Vice-diretor & Não se aplica \\
\hline Carolina & $\begin{array}{l}\text { Licenciatura e Bacharelado em } \\
\text { Química }\end{array}$ & $\begin{array}{l}\text { Professora de } \\
\text { Ciências e Quí- } \\
\text { mica }\end{array}$ & $\begin{array}{l}6^{\circ} \text { ano do EF, } \\
\text { todas do EM e } \\
\text { EJA }\end{array}$ \\
\hline Kysla & $\begin{array}{l}\text { Licenciatura em Matemática } \\
\text { e Pedagogia } \\
\text { Pós-graduação em violência infantil } \\
\text { e doméstica }\end{array}$ & $\begin{array}{l}\text { Professora } \\
\text { coordenadora } \\
\text { pedagógica }\end{array}$ & Não se aplica \\
\hline Luís & $\begin{array}{l}\text { Licenciatura em História e Pedagogia } \\
\text { Pós-graduação em Educação }\end{array}$ & $\begin{array}{l}\text { Professor de } \\
\text { História }\end{array}$ & $\begin{array}{l}9^{\circ} \text { ano do EF, } \\
\text { todas do EM e } \\
\text { EJA }\end{array}$ \\
\hline Mônica & $\begin{array}{l}\text { Licenciatura e bacharelado em } \\
\text { Ciências Sociais }\end{array}$ & $\begin{array}{l}\text { Professora de } \\
\text { Sociologia e } \\
\text { Geografia }\end{array}$ & $\begin{array}{l}\text { Todas do EM } \\
\text { e EJA }\end{array}$ \\
\hline Patrícia & $\begin{array}{l}\text { Licenciatura em Matemática } \\
\text { Pós-graduação em Docência no Nível } \\
\text { Superior }\end{array}$ & $\begin{array}{l}\text { Professora de } \\
\text { Matemática e } \\
\text { Física }\end{array}$ & $\begin{array}{l}2^{\mathrm{a}} \text { e } 3^{\mathrm{a}} \text { séries do } \\
\mathrm{EM}\end{array}$ \\
\hline Tânia & $\begin{array}{l}\text { Licenciatura em Pedagogia } \\
\text { Licenciatura em Psicologia }\end{array}$ & Diretora & Não se aplica \\
\hline
\end{tabular}

Fonte: As autoras. 
A obtenção de dados para a pesquisa foi realizada através de uma entrevista coletiva, feita com o corpo de professores, e entrevistas individuais com membros da equipe gestora - professora coordenadora pedagógica, vice-diretor e diretora. Professores e professora coordenadora responderam questões relacionadas com as especificidades sociais e pedagógicas da inclusão de pessoas trans. Já aos membros da direção da escola foram feitos questionamentos sobre ações e dificuldades da escola para tal acolhimento.

O tratamento dos dados se deu pela análise de discurso. Este método possibilita buscar o que está explícito e o que está implícito nas falas, permitindo investigar os significados e representações da cultura que os discursos carregam (NOGUEIRA, 2001).

A análise de discurso não se propõe a desvelar a totalidade de sentidos que estão atrelados aos discursos, mas sim buscar a profundidade de determinados aspectos (ORLANDI, 2007) delimitados pela lente teórica. Para a autora (2009, p. 15), “A Análise de Discurso concebe a linguagem como mediação necessária entre o homem e a realidade natural e social" , que exterioriza para o mundo o pensamento, carregando embebida em si a história e a ideologia que a influenciaram. Assim, a análise de discurso se interessa pelas condições que geram produção de sentido de determinados enunciados dos sujeitos. Os movimentos sociais, conteúdos midiáticos, imposições morais, paradigmas religiosos, dentre outros, influenciam na produção de enunciados. A imersão do sujeito na sociedade o faz introjetar em si as realidades desse meio.

Ressaltamos que o projeto de pesquisa que resultou neste artigo obteve aprovação pelo Comitê de Ética em Pesquisa da universidade na qual o mestrado foi realizado e que os sujeitos assinaram o Termo de Consentimento Livre e Esclarecido. A fim de garantir o anonimato dos sujeitos de pesquisa e de discentes citados nos relatos, os nomes foram substituídos por pseudônimos.

\section{Resultados e discussão}

Ao olhar para o grupo de sujeitos de pesquisa, composto por profissionais de quatro diferentes funções que atuam no chão 
da escola, buscamos enxergar as diferentes posições de sujeito que um docente pode desempenhar dentro do discurso de "aceitação" de pessoas trans. Buscamos estranhar a "aceitação" na escola. Estranhar que, mesmo com todos os direitos, as pessoas trans ainda estão sujeitas a serem "aceitas" para exercer sua humanidade em toda a sua magnitude. Docentes que se encontram atuando como professor ou professora acabam por ter mais liberdade de expressar suas opiniões por dois motivos: estar entre seus pares enquanto entrevistados em grupo e não ter a pressão de reproduzir certos discursos devido ao cargo de liderança. Assim, entendemos que estamos observando ao menos quatro diferentes condições de produção de discursos.

Dizemos observar como se dá a "aceitação" da pessoa trans por tal termo ter surgido espontaneamente nas falas dos docentes, já no início do grupo focal, quando questionados sobre as dificuldades de receber estudantes nessa condição. O grupo de professores discute que não existem dificuldades por parte deles próprios, os docentes, mas sim por parte de outros estudantes. O termo "aceitação", contudo, é no mínimo incoerente, visto que a inclusão dessas pessoas no seio do ambiente escolar já está posta, tanto pela legislação que garante a "igualdade de condições para o acesso e permanência na escola" (BRASIL, 1996), quanto pela prática, já que as pessoas trans existem. Para existirem como sujeitos de direitos, as pessoas trans não dependem de autorização ou "aceite" de ninguém. Entretanto, "aceitação" e outras palavras derivadas do mesmo radial aparecem nos discursos delimitando "A Linha" (RUBIN, 2003, p.26) de tolerância às sexualidades não hegemônicas, ora pelos próprios docentes, ora representando sua percepção da tolerância de discentes.

Segundo os docentes, a inclusão de pessoas trans se dá de maneira fácil, sem entraves por sua parte, não se percebendo como sujeitos que poderiam causar a dificuldade para a permanência de pessoas trans na escola. Quando questionados sobre essas dificuldades de receber alunos trans, apontam:

Mas se os alunos aceitam é fácil você trabalhar. Eu nunca peguei uma sala 
que não aceitasse (Professora Carolina).

Não tive dificuldades nenhuma. Tratamento normal dos alunos. Parece que ... Não sei. Até penso que, hoje em dia, esses adolescentes, eles estão respeitando mais essa questão. Aceitando mais [...] (Professor Luís).

Mesmo sendo apontado na literatura que o corpo docente e funcionários são os grandes dificultadores da permanência de docentes trans (CANTELLI; NOGUEIRA,2019), o grupo de professores não se percebe dessa maneira. O professor Luís aponta que a "aceitação" facilitada se deve ao recente respeito dos adolescentes. Isto levanta a questão "adultos, incluindo aí professores, se mostram relutantes para 'aceitar' tais discentes?'”. As questões geracionais, com as atuais discussões e expressões da diversidade sexual, sobretudo na internet, poderiam amparar a discrepância entre adolescentes e adultos, uma vez que os jovens estão menos contaminados com tabus criados por experiências anteriores. Ao confrontar com a fala da professora coordenadora nos deparamos com a afirmação de que docentes seriam os responsáveis por essa não "aceitação".

É claro que sempre tem aqueles que fazem uma brincadeirinha indevida, mas rejeição, não. As pessoas foram muito bem aceitas

O quadro (docente), na época, acho que aceitou numa boa. Se teve alguém que aceitou por alguma legislação, talvez esses que fizeram uma piadinha aqui uma piadinha ali, mas não fez nenhuma discriminação (Professora coordenadora pedagógica Kysla).

Usar os termos "brincadeirinha" e "piadinha" no diminutivo busca, ao mesmo tempo, evidenciar e abrandar o problema. No entanto, como apontado por Junqueira (2012), a pedagogia do insulto, caracterizada pelas "piadinhas" cotidianas, é um eficiente recurso da Pedagogia do Armário, como forma de silenciamento das sexualidades não hegemônicas. $\mathrm{O}$ autor ressalta que:

As "brincadeiras" heterossexistas e homofóbicas (não raro, acionadas como recurso didático) constituem-se poderosos mecanismos heterorre- 
guladores de objetivação, silenciamento (de conteúdos curriculares, práticas e sujeitos), dominação simbólica, normalização, ajustamento, marginalização e exclusão (JUNQUEIRA, 2012, p. 69).

A professora Patrícia, ao falar de experiências do início de sua carreira docente, aponta que "Muitas pessoas se escondiam atrás do medo". O medo de expressar-se fora dos padrões cis/heteronormativos no interior da escola poderia estar ligado à falta de "aceitação" social, especialmente o preconceito dirigido pelos adultos. Isso é corroborado pelos dados observados por Andréia Cantelli e Sayonara Nogueira (2019). As pesquisadoras apontam que em 73\% dos casos a imposição de obstáculos para a permanência de discentes trans é realizada por funcionários, sejam eles docentes, gestores ou outros membros da equipe pedagógica (CANTELLI; NOGUEIRA, 2019).

Por outro lado, o vice-diretor Carlos ressalta a mudança da sociedade atual quanto à receptividade às pessoas de sexualidade não hegemônica.

Eu acho assim, que no mundo de hoje, é normal. Tem que tratar como ela quer ser tratada, na verdade. Eu acho que mudou muito hoje em dia. Não é aquele método tradicional, antigo. Hoje é outra realidade, na verdade. Antigamente eles escondiam e hoje não, já aberto ao público (Vice-diretor Carlos).

$\mathrm{Na}$ visão do gestor, na contemporaneidade, haveria mais abertura à exposição pública da autoidentificação, a chamada "saída do armário", pois a "aceitação" social seria maior do que a encontrada em outros tempos, com uma perspectiva educacional mais tradicional. Julia Serrano (2007) também aponta para um aumento na liberdade de autoidentificação. $\mathrm{O}$ vice-diretor enuncia ainda que "no mundo de hoje, é normal". Com a exposição pública da própria identidade a pessoas trans seria vista como "normal"? Para Rogério Junqueira (2012, p.66), a delimitação da normalidade se dá em características "centradas no adulto, masculino, branco, heterossexual, burguês, física e mentalmente 'normal". Para o autor, 
pessoas que estão fora desse padrão, no interior da escola (espaço que circulam diversas discriminações e preconceitos), seriam vistas como "outro", que é "considerado estranho, inferior, pecador, doente, pervertido, criminoso ou contagioso" (p.65)

Para além da equipe escolar, o sucesso escolar das pessoas trans pode perpassar outras áreas da vida desses estudantes. Durante o grupo focal, foi apontado o impacto da "não aceitação" familiar no seguinte trecho:

O rendimento escolar, antes, na outra escola que eu estou falando, que era um menino depois virou uma menina, e que não era assumido ainda, era pouco assumido, nesse caso, ela caiu bastante o rendimento. Eu não sei se porque ele entrou em crise psicológica, ele entrou com problemas psicológicos. A mãe não aceitava. A família não aceitava. Ele resolveu enfrentar tudo e todos e, de repente, não foi tão fácil para ele assim. Então ele teve uma queda brusca no rendimento escolar sim (Professora Patrícia).

No relato da Professora Patrícia, a aluna trans se vendo vítima de preconceitos e violências tanto no interior da escola quanto no seio familiar, passou a apresentar uma queda no seu desempenho e aprendizado. Sem espaços de escuta e esclarecimento de dúvidas na família, por ser impedida de expressar-se como é, a pessoa "acaba tendo que descobrir sozinha” (PERES, 2009, p. 260) gerando impactos muito grandes que podem acabar atrapalhando os estudos.

Por outro lado, a equipe de professores considera que, quando amparados pela família, discentes trans podem manter o rendimento. Para exemplificar a manutenção do rendimento quando apoiada pela família, o grupo de professores relembra a vivência com outro aluno trans, que para garantir o sigilo de identidade aqui será denominado João/Joana. João é um rapaz trans que realizou seu processo de redesignação de gênero durante o período que estava na escola.

João, ao expressar sua identidade de gênero, teve apoio familiar na exposição pública da sua autoidentificação, como pode ser visto no seguinte diálogo:

A (família) do João, pesquisadora, a mãe dele estava aqui. A mãe dele era do EJA e 
ele do regular e a mãe dele tranquilamente, ela falava com a gente "o João, tá fažndo as coisas?". Ela mesma, a mãe dele, eu não sei em relação ao pai, mas ele era muito bem resolvido. Não sei do pai, mas a mãe estudava aqui. A gente conversava com ela... (Professora Mônica).

Ainda sobre o aluno João, os professores relatam que sua conduta se manteve, não apresentando mudanças no seu aprendizado e rendimento ou dificuldades de socialização:

Professora Mônica: a Joana continuou do mesmo jeito. Ela não mudou nada. Nem nada antes nem nada depois. Ela continuou igual, não mudou nada.

Professor Luis: Dispersa, tinha que ficar cobrando o tempo todo.

Professora Mônica: Por isso que eu chamava o tempo todo o nome.

Professor Luís: Não alterou isso aí. Nesse sentido.

Professora Mônica: Ela, ele não alterou nada.

Professora Patrícia: É que gostava de falar bastante.

Professor Luis: e a família toda apoiava.

Ainda que as falas tivessem a intenção de discutir as questões de rendimento escolar, traz um ponto importante sobre a "aceitação" docente desses discentes. A insistente utilização do pronome feminino durante todo o grupo focal, quando referindo a João, mesmo após o aluno ter solicitado o nome social masculino, para além do hábito que já tinha ao falar com o aluno, demonstra certa resistência de docentes para "aceitar" a autoidentificação do aluno.

O mesmo acontece na fala, já citada anteriormente, da professora Patrícia: "que era um menino depois virou uma menina, e que nãa era assumido ainda, era pouco assumido, nesse caso, ela cain bastante o rendimento. [...] Ele resolveu enfrentar tudo e todos e, de repente, não foi tão fácil para ele assim". A docente intercala entre pronomes femininos e masculino ao se referir à aluna, demonstrando sua não "aceitação" da autoidentificação, ainda que tente manter a fala esperada socialmente. Além disso, aponta um gradiente entre ser "não assumido", "pouco assumido" e finalmente "virar uma menina", demarcando "A Linha" (RUBIN, 2003, p.26) de transgressão que ela própria entende no processo de redesignação de gênero. 
Outro dificultador da permanência de pessoas trans na escola que pode ser facilmente observado no cotidiano é o uso do banheiro, como já relatado por Cruz (2011). Tal questão, levantada espontaneamente pelos docentes durante suas falas, demonstra a angústia do grupo por assuntos que estão no âmbito privado da vida da pessoa trans, mas muito colocado em evidência quando se discute a inclusão de pessoas trans na escola ou no mercado de trabalho. Dentro do grupo focal, a docente Patrícia foi a primeira a trazer o assunto relatando sua vivência em outra unidade.

\begin{abstract}
No passado, não só no grupo escolar, como nessa mudança repentina que houve, eles se sentiam mal de usar o banheiro. Eles falavam que como ele não se via homem mais, se via do sexo mulher, ele queria utilizar o banheiro das mulheres e as mulheres não aceitavam porque ele, há um semestre anterior, ele era homem. Então teve muita confusão na escola que nós trabalbávamos porque ele queria usar o banheiro feminino, só que era um homem até um tempo atrás, então a mulherada, as moças, não aceitavam. "Que um homem tá usando nosso banheiro"? "Não, não, não”. Então houve um certo tipo "não aceito", "Não quero”, "não quero a sua presença”. Tipo... achando que ele era um mentiroso. Ainda se passando por mentiroso. "Você não mudou de sexo coisa nenhuma. Você quer ver as meninas usando o banheiro". Então achavam que ele estava brincando com aquilo e que não ia ceder banheiro nenhum, que ele tinha que continuar usando o banheiro dos homens (Professora Patrícia).
\end{abstract}

Em todo o trecho a docente se refere a mesma aluna trans, já referida em outros trechos, utilizando o pronome masculino, conotando a sua não "aceitação" da autoidentificação da discente. Trazendo a frase "achando que ele era um mentiroso. Ainda se passando por mentiroso", Patrícia levanta que, na opinião dos alunos, a aluna se falseava em uma identidade que não lhe pertencia, uma vez que "o" viam como "um mentiroso". Transgredindo padrões de gênero e sexualidade o sujeito embarca numa luta com ideias conservadoras (LOURO, 2004) que permanecem deslegitimando sua autoidentificação. Com o gatilho disparado por Patrícia, a questão do banheiro ganhou espaço na em uma interação com outra docente em outro momento posterior: 
Professora Mônica: E esse negócio de banheiro? É complicado isso aí. Eu não queria ser diretora de uma escola e ter que passar por esse tipo de situação.

Professora Patrícia: Porque na casa da gente é um banheiro único para todos usarem e na escola é dividido justamente por causa da criançada

Professora Mônica: Eu acho que eles deveriam ir aos banheiros conforme eles se identificam. O problema não são eles. O problema é como os outros vão aceitar aquilo.

Professora Patricia: A sociedade vai aceitar?

Professora Mônica: Principalmente o menino nas meninas. Porque tem o órgão sexual, tem o pênis. Pensou o menino fazendo xixi e a menininha...

Professora Patrícia: Vai criar uma polêmica que vai criar danos para sociedade. Como a escola vai deixar isso acontecer? Não pode. Então eles são excluidos. Não deixa de jeito nenhum usar.

Quais seriam os "danos à sociedade" que o "xixi” das pessoas trans traria? Seriam danos à ordem disciplinadora que a escola permanece reproduzindo. Mas o que importa a essa ordem? "De uma luta contra a sexualidade? De um esforço para assumir o controle? De uma tentativa de melhor regê-la e ocultar o que ela comporta de indiscreto, gritante, indócil?" (FOUCAULT, 1988, p. 100). Desejando não se ver em uma posição de liderança ao receber pessoas trans na escola, os professores demonstram que tais discentes trariam quebra de ordem ao bom andamento da escola como formadora de corpos submissos.

Para além dos padrões de comportamento, valora-se demasiadamente a genitália. As professoras Mônica e Patrícia ressaltam em sua interação o "dano" de uma pessoa que possui "órgão sexual" estar num banheiro feminino. Mas todos nós não temos órgãos sexuais? $\mathrm{Na}$ fala da professora, ela se refere ao pênis, parafraseando enunciados de grupos conservadores que realizam do masculino. Há a hipervalorização do falo em detrimento de outras genitálias possíveis.

A discussão das docentes sobre o uso do banheiro reflete o tal "dano à sociedade" que está no imaginário das pessoas, devido a discursos conservadores, que temem que uma pessoa com pênis, por estar em um banheiro feminino, possa violar as demais usuárias do ambiente. Esse imaginário é refletido nos índices de homicídios 
de pessoas trans, onde as vítimas são majoritariamente trans femininas (BENEVIDES, 2018, BENEVIDES; NOGUEIRA, 2019).

Berenice Bento (2011) denomina essa preocupação demasiada com as genitálias como genitalização das relações sociais, que é uma tecnologia discursiva que colabora com o preparo para o desempenho dos papéis de gênero. Já antes do nascimento, ao fazer a sexagem fetal, outorga-se à humanidade àquele ser com base em sua genitália, pois a humanidade estaria atrelada à capacidade performática de gênero, "produzindo masculinidades e feminilidades condicionadas ao órgão genital" (BENTO, 2011, p. 551).

Dada à inquietude dos professores quanto à utilização do banheiro, o assunto tornou-se pauta na entrevista com a diretora. Os entraves logísticos citados pelo grupo de professores sobre a questão foram apresentados, aos quais ela respondeu da seguinte maneira:

As pessoas que tiveram essa modificação aqui, essa transformação aqui, aí no caso era a menina, continuou usando o banheiro feminino. Do rapaz que eu saiba, sinceramente, nunca foi levantado essa questão. E eu, sinceramente, não sei que banheiro ele usava (Diretora Tânia).

É possível perceber que, embora sabidamente problemática na maioria dos espaços, nessa unidade especificamente, aparentemente, não houve dificuldades quanto a isso, visto que não ganhou visibilidade a ponto de chegar à direção. Mesmo assim, a gestora aponta caminhos que seriam adequados a seu ver.

[...]Eu acho que seria mais adequado que ele usasse o banheiro feminino. Não sei eu vou até perguntar se alguém sabe se ele vai no banheiro..., mas eu acho que não teria problema com relação a isso também. Porque se fosse o caso, eu passaria de sala em sala conversaria com os alunos, explicaria a situação, e eu acho que não teria problema não. Porque são individuais os boxes ali, então... eu só acho que seria um pouco constrangedor para ele frequentar o banheiro masculino, porque os homens estão pouco mais resistentes a essas questões [...] (Diretora Tânia). 
Ao mostrar que entende que homens são "mais resistentes a essas questões", a diretora usa valores da ideia de que os comportamentos definidos pelos estereótipos de gênero são dados e inevitáveis (WEEKS, 2000), uma vez que ela mesma não observou resistência de homens ao receber pessoas trans. Para afirmar sobre essa resistência dos homens, a diretora Tânia se vale da paráfrase de discursos cisnormativos de comportamento já naturalizados.

Todavia, ao contrário dos professores, a diretora não apresenta sua percepção presa à genitalização das relações sociais, pois cita a estrutura arquitetônica dos boxes do banheiro para garantir que a genitália permanece no âmbito privado, independentemente de estar no interior da escola. Tomando seu papel na posição de sujeito de gestora escolar, Tânia ainda ressalta que "passaria de sala em sala conversaria com os alunos", conotando se reconhecer como principal facilitadora do acesso dessas pessoas à escola e manutenção do seu bem-estar.

De forma prática, a inclusão de pessoas trans, por vezes, encontra dificuldades. A escola em questão, tem uma diretora que busca fazer esse recebimento da maneira mais tranquila para o discente. A diretora, com base na sua experiência, conta que:

Eu acho que quando a gente aceita com naturalidade, as coisas fluem naturalmente. A gente vive um dia de cada vez. Eu acho que as coisas vão se transformando, as pessoas vão se transformando, vão se tornando aquilo que gostaria de ser. Eu acho que as coisas... foi assim se a gente não chama muita atenção para determinadas coisas, se a gente encara com naturalidade, as coisas acontecem com naturalidade. Então aqui eu procuro fazer isso (Diretora Tânia)

A gestora acredita que, como líder daquela equipe escolar, é de vital importância para que o processo se dê de maneira adequada, pois uma vez passando tranquilidade, essa tranquilidade também será refletida pelos demais membros da comunidade escolar. William Peres (2009) destaca que gestores atentos à vulnerabilidade a que estão sujeitas as pessoas trans no ambiente escolar estimulam 
ações que valorizam a expressão livre das sexualidades divergentes dos padrões hegemônicos. Neste sentido, a diretora relata uma experiência positiva com outro membro da comunidade:

[...]todo mundo aceitou muito bem, os alunos, os colegas de classe, não teve nenhum deboche, nenhuma situação de constrangimento que eu tenha tido conhecimento, todo mundo aceitou. Inclusive, da funcionária que passou pela transformação aqui na escola. Então ela chegou com características femininas e aos poucos foi se transformando, pediu para... comentou que ia pedir transferência por conta disso, para não haver problema para escola e aí eu disse que não ia. Se ela pedir a transferência por conta disso, que eu não aconselharia porque eu acho que é uma experiência bastante rica para nós, para a gente aprender a lidar com determinadas situações. Perguntei se ela tinha se ela era respeitada de alguma forma, se alguém a constrangia, se alguém fazia algum comentário, alguma criança... ela disse que não. Que ninguém fez comentário nenhum, que ninguém nunca desrespeitou e tal. Eu falei então deixa acontecer, vai vivendo e a gente também vai vivendo essas transformações. E foi assim supertranquilo[...] (Diretora Tânia).

O trecho se refere a um funcionário trans da unidade escolar, que tinha exposto recentemente sua autoidentificação e temia causar problemas por estar no seu período de transição. $O$ temor das pessoas trans em permanecer no interior da escola é relacionado com a violência e o preconceito, muitas vezes legitimados pelo corpo de funcionários (PERES, 2009). Para abrandar esse temor, a diretora destaca a experiência como muito rica para a comunidade, deixando evidente que não permitiria, como gestora, que essas violências fossem praticadas ali.

Ao possibilitar essa experiência à comunidade da sua escola, a diretora apresenta uma nova perspectiva quanto à sexualidade. Demonstrar que a sexualidade hegemônica heterossexual não é natural, mas sim é uma das possibilidades de se viver e expressar a sexualidade, dentre outras tantas possíveis (ALVARENGA; DAL'IGNA, 2013), gerando um poder emancipatório pelo conhecimento das diversidades. A diretora Tânia concluiu relembrando que: 
[...] eu também já tive os meus preconceitos e a gente aprende a se livrar deles quando a gente convive. Acho que a convivência é a melhor forma disso. Eu acho que é bem rico a gente proporcionar isso. A escola tem essa abertura, em todos os sentidos, não é só com relação à trans, com qualquer outro tipo de situação. Eu acho que todo mundo ganha, não é? (Diretora Tânia).

Como vivência pessoal, a diretora Tânia percebe a importância de conhecer e poder conviver com a diversidade que a sexualidade pode apresentar como forma de desconstruir tabus aprendidos ao longo da própria história. Como gestora, por ter autonomia de escolha sobre diversos aspectos do andamento da escola, Tânia se vê como facilitadora para que a visibilidade das sexualidades não hegemônicas e a quebra de tabus ocorram. Mary Neide Figueiró (2014) denomina esse questionamento e quebra de paradigmas de reeducação sexual, onde o sujeito se livra de valores impregnados na própria formação. Ao possibilitar a reeducação sexual no interior da escola, abre-se caminho para, no futuro, receber a pessoa trans nos diferentes espaços.

\section{Considerações finais}

A “aceitação" da pessoa trans no ambiente escolar esbarra em padrões estabelecidos dentro de visões tradicionais da sexualidade, onde os comportamentos de cada gênero estariam atrelados à genitália. A genitalização das relações sociais e a hipervalorização do falo é observada especialmente na preocupação dos professores com a utilização do banheiro.

A deslegitimação da autoidentificação da pessoa trans é recorrente, ainda que os docentes não se percebam como dificultadores da permanência dessas pessoas no interior da escola. Demonstra-se nesse sentido que, apesar de permanecerem presos a tabus e paradigmas construídos na sua própria vivência, estes docentes estão abertos a realizar esforços para que as pessoas trans sejam bem acolhidas.

Para que a pessoa trans se sinta bem ao permanecer na escola necessita tanto do apoio familiar quanto do acolhimento adequado 
da equipe escolar. E para que esse acolhimento seja feito de forma eficiente é necessário que a comunidade, através da mediação da gestão, encare o processo com naturalidade. A transgeneridade é uma entre tantas facetas que fazem parte da construção daquele indivíduo que tem direito de se expressar de forma livre também no ambiente escolar.

\section{Referências}

ALVARENGA, Luiz Fernando Calage; DAL'IGNA, Maria Claudia. Corpo e sexualidade na escola: as possibilidades estão esgotadas? In.: MEYER, Dagmar; SOARES, Rosângela (Org). Corpo, gênero e sexualidade. $3^{\text {a }}$ ed. Porto Alegre: Mediação, 2013.

BENTO, Berenice. O que é transexualidade? São Paulo: Brasiliense, 2008.

BENTO, Berenice. Na escola se aprende que a diferença faz a diferença. Revista Estudos Feministas, v. 19, n. 2, p. 549-559, 2011.

BENTO, Berenice. Transviad@s: gênero, sexualidade e direitos humanos. Salvador: EdUFBA, 2017.

BENEVIDES, Bruna, Mapa de assassinatos de transexuais e traves no Brasil em 2017. Brasília: ANTRA, 2018.

BENEVIDES, Bruna; NOGUEIRA. Sayonara Naider Bonfim (Org). Dossiê: Assassinatos e violência contra transexuais e travestis no Brasil em 2018. Brasília: Distrito Drag, ANTRA, IBTE, 2019.

BRASIL. Lei de Diretrizes e Bases da Educação Nacional. Lei número 9394, 20 de dezembro de 1996.

CANTELLI, Andréia Lais; NOGUEIRA, Sayonara Naider Bonfim. A realidade das/os estudantes trans no Brasil. In CANTELLI, Andréia Lais; PEREIRA, Fernanda Ribeiro, OLIVEIRA, Julia Jorge de; TOZO, Nicholas Lopes; NOGUEIRA, Sayonara Naider Bonfim. As fronteiras da educação: A realidade dxs estudantes trans no Brasil. Brasília: IBTE, 2019.

CRUZ, Elizabete Franco. Banheiros, travestis, relações de gênero e diferenças no cotidiano da escola. Revista Psicologia Política, São Paulo, v. 11, n. 21, p. 73-90, jan./jun. 2011. 
DECLARAÇÃO UNIVERSAL DOS DIREITOS HUMANOS. Assembleia Geral das Nações Unidas em Paris. 10 dez. 1948. Disponível em <https://www. ohchr.org/EN/UDHR/Pages/Language.aspx?LangID=por $>$. Acesso em 30 de dezembro de 2019.

FIGUEIRÓ, Mary Neide Damico. Formação de educadores sexuais: adiar não é mais possível. 2.ed. Londrina: EDUEL, 2014.

FOUCAULT, Michel. História da sexualidade: A vontade de saber. Rio de Janeiro: Graal. 1988. v.1

JESUS, Jaqueline Gomes de. (Org). Transfeminismo: teorias e práticas. Rio de Janeiro: Metanoia Editora, 2014.

JUNQUEIRA, Rogério Diniz. A Pedagogia do Armário: heterossexismo e vigilância de gênero no cotidiano escolar. Revista Educação On-line PUC, Rio de Janeiro, n. 10, p. 64-83, 2012.

LOURO, Guacira Lopes. Um corpo estranho: ensaios sobre a sexualidade e teoria queer. Belo horizonte: Autêntica, 2004.

MARANHÃO FILHO, Eduardo Meinberg de Albuquerque. "É prá baixar o porrete!" Notas iniciais sobre discursos punitivos/discriminatórios acerca das homossexualidades e transgeneridades. Mandrágora, v. 21, n. 21, p. 47-84, 2015.

NAVARRO-SWAIN, Tânia. Todos somos Queers: identidade e sexualidade. In: Desafiando a diferença: gênero, raça e classe, 2000, Salvador. Desafiando a diferença, 2000 .

NOGUEIRA, Conceição. A análise do discurso. In. Almeida, L; Fernandes, E. (Edits), Métodos e técnicas de avaliação: novos conhecimentos para a prática e investigação. Braga: CEEP, 2001.

ORLANDI, Eni Puccinelli. Educação em direitos humanos: um discurso. In. SILVEIRA, Rosa Maria Godoy, et al. Educação em Direitos Humanos: Fundamentos teórico-metodológico João Pessoa: Editora Universitária, 2007.

ORLANDI, Eni Puccinelli. Análise de Discurso: princípios \& procedimentos. 8. ed. Campinas: Pontes, 2009.

PERES, Wiliam Siqueira. Cenas de Exclusões Anunciadas: travestis, transexuais, transgêneros e a escola Brasileira. In. JUNQUEIRA, Rogério Diniz. Diversidade Sexual na Educação: problematizações sobre a homofobia nas escolas. Brasília: 
Ministério da Educação, Secretaria de Educação Continuada, Alfabetização e Diversidade, UNESCO, 2009.

PRINCÍPIOS DE YOGYAKARTA. Princípios sobre a aplicação da legislação internacional de direitos humanos em relação à orientação sexual e identidade de gênero. Brasília, Secretaria Especial dos Direitos Humanos, 2007.

RUBIN, Gayle. Pensando sobre sexo: notas para uma teoria radical da política da sexualidade. Cadernos Pagu, Campinas, n. 21, pp. 1-88, 2003.

SERRANO, Julia. Whipping Girl: a transsexual woman on sexism and the scapegoating of femininity. Emeryville: Seal Press, 2007.

STF. Supremo Tribunal Federal. Provimento n. 73, de 28 de junho de 2018. Disponível em <https://www.migalhas.com.br/arquivos/2018/7/art20180702-02. pdf $>$. Acesso em 19 de março de 2020.

WEEKS, Jeffrey. O corpo e a sexualidade. In: Louro, Guacira Lopes. (Org). O corpo educado: pedagogias da sexualidade. Belo Horizonte: Autêntica, 2000.

Submetido em: 20-11-2020

Aceito em: 27-7-2021 